\title{
Correlation of endometrial thickness by Trans-Vaginal Sonography [TVS] and histopathology in women with abnormal peri-menopausal and postmenopausal bleeding - A prospective study
}

\author{
P. Thulasi ${ }^{1, *}$, Balakrishnan R. ${ }^{2}$, Shanthi M. ${ }^{3}$ \\ ${ }^{1,2}$ Associate Professor, ${ }^{3}$ Senior Resident, dept. of Obstetrics and Gynaecology, P K. Das Institute of Medical Sciences, \\ Vaniamkulam, Kerala, India \\ *Corresponding Author: \\ Email: drpthulasi@rediffmail.com
}

\begin{abstract}
Abnormal Uterine Bleeding (AUB) affects 50\% of peri-menopausal women. It is common during the extremes of reproductive life, following pregnancy and also during lactation. About 10-15\% of women experience AUB sometime during reproductive years of their lives.Irrespective of their age most of the women experience abnormal uterine bleeding at some or the other time.

Objectives of the study: To ascertain the effectiveness of trans-vaginal ultrasound (TVS) to determine the endometrial thickness and its correlation with histopathology in abnormal uterine bleeding.

Materials and Methods: This was a prospective study carried out in the department of Obstetrics and Gynecology with contribution from the department of Radiodiagnosis also, at P K Das Institute of Medical Sciences over a period of one year. The study included 75 women in the peri-menopausal and postmenopausal period who had presented with chief complaints of abnormal uterine bleeding. Patients were selected from OPD. Trans-vaginal sonography was done. Endometrial thickness was measured and was correlated with histopathology report after dilatation and curettage.

Results: The age distribution of patients, clinical presentation, endometrial thickness by trans-vaginal ultrasound, endometrial hyperplasia as estimated by endometrial thickness and various histopathological patterns of endometrium on 75 patients were analyzed. Majority of the patients were between 40-45 years in the present study. Among 75 patients, menorrhagia was present in 30 cases [40\%]. Endometrial thickness between 8 to $10 \mathrm{~mm}$ was seen in 35 patients (46.66\%), endometrial thickness between 10 to $15 \mathrm{~mm}$ was seen in 15 cases $(20 \%)$, whereas, only 4 cases $(5.33 \%)$ had endometrial thickness more than or equal to $15 \mathrm{~mm}$. Endometrial hyperplasia was seen in 30 patients $(40 \%)$ followed by proliferative endometrium in 25 patients $(33.33 \%)$. Among 30 patients of endometrial hyperplasia, only 2 patients (6.66\%) had atypical hyperplasia. Majority $66.66 \%$ had simple hyperplasia.

Conclusion: In peri-menopausal and postmenopausal AUB, trans-vaginalsonography should be the first investigation of choice. In peri-menopausal women, dilatation and curettage is recommended if endometrial thickness exceeds $10 \mathrm{~mm}$ to rule out any hyperplastic process. Endometrial thickness of $5 \mathrm{~mm}$ should be taken as the upper limit for postmenopausal women.
\end{abstract}

Keywords: Abnormal Uterine Bleeding (AUB), Endometrium, Trans-vaginalsonography (TVS), endometrial thickness, histopathology, endometrial hyperplasia.

\section{Introduction}

Abnormal uterine bleeding is one of the common presenting complaints encountered by a gynecologist. ${ }^{1}$ It is common during the extremes of reproductive life, following pregnancy and during breast feeding. It is also common irrespective of the age of women. AUB affects $50 \%$ of peri-menopausal women. The type of investigationsare different for different age groups. Endometrial carcinoma is another common condition that is seen with advancing age and this condition also presents frequently as AUB. Hence, thorough evaluation of all AUB cases is a must.

Anovulation is considered as the most common cause of AUB in premenopausal women. Hence, for these patients investigations are directed at finding out the reasons foranovulatory cycles. Hyperplasia of endometrium or the more ominous condition of endometrial carcinoma is more common in peri or postmenopausal age which is diagnosed by endometrial biopsy. In postmenopausal women, the various types of endometrial carcinomas aremore common. So TVS / endometrial biopsy are done as the initial investigations for these patients.

Transvaginal ultrasound should be the first imaging test to be undertaken for evaluation of AUB. ${ }^{2}$ Transvaginal ultrasound gives better resolution as it is done in close proximity to the uterus. ${ }^{3}$

Abnormal peri-menopausal bleeding has to be evaluated for endometrial hyperplasia or carcinoma. ${ }^{4}$ Postmenopausal bleeding is a common clinical presentation in today's world due to increased longevity of the population in general, due to increased obesity and also wide spread use of hormone therapy. ${ }^{5}$

In peri-menopausal women with AUB, endometrial pathology is easily picked up on histopathology by collecting the tissue sample on dilatation and curettage. Significant endometrial pathology is detected in almost $10 \%$ of postmenopausal women. Using a non-invasive technique such as TVS is preferable at the first instance for detecting endometrial lesions and followed by the invasive technique of dilatation and curettage later. 
In our study we attempted to correlate the effectiveness of transvaginal ultrasound with histopathology of endometrium by sample collected by dilatation and curettage.

\section{Objectives of the study}

1. To determine the efficacy of transvaginal ultrasound in depicting the pattern of endometrium

2. To correlate transvaginal endometrial thickness with histopathology of endometrium in AUB.

\section{Materials and Methods}

A total of 75 patients who presented to the Gynecology OPD with clinical presentation of abnormal uterine bleeding were studied. These patients were in peri-menopausal and postmenopausal age groups. They were referred to the department of Radiodiagnosis for transvaginal ultrasound examination. Endometrial thickness was measured andand documented. A transducer of $7.5 \mathrm{MHz}$ was used during menstrual cycle and the endometrial thickness was measured in the sagittal plane.This was followed by the dilatation and curettage procedure.

\section{Inclusion criteria}

1 Women 40 years of age (peri-menopausal) and menopausal with AUB

\section{Exclusion criteria}

1. Patients with AUB in other age groups

2. Carcinoma of the genital tract

3. Pregnancy

The longitudinal axis of the uterus was used to identify the endometrial tissue. The plane where the endometrial cavity was to be followed from cervical canal to upper fundal border of uterine cavity was identified and endometrial thickness was measured. The three distinct layers identifiable in the longitudinal view are the outermost layer of perimetrium, the middle thick layer of myometrium and the innermost lining endometrium. The endometrium is highly echogenic and has a surrounding hypoechogenic area of inner myometrium. The measurement is taken from basalis anterior to contra lateral basalis (posterior) part. In the present study,measurement of the full thickness of endometrium was performed and the thickest portion of the endometrium was considered. The best plane for measuring the endometrium is the Antero - Posterior (AP) pelvic plane.

\begin{tabular}{|l|l|}
\hline \multicolumn{1}{|c|}{ Sonographic findings } & \multicolumn{1}{|c|}{ Atypical Patterns } \\
\hline Uniform thin echogenic line & Atrophic endometrium \\
\hline $\begin{array}{l}\text { Abnormally thick endometrium with } \\
\text { multiple small cystic spaces (Swiss cheese } \\
\text { endometrium) }\end{array}$ & Cystic glandular endometrium \\
\hline $\begin{array}{l}\text { Thickening of endometrial stripe appearing } \\
\text { homogeneously echogenic }\end{array}$ & Endometrial hyperplasia \\
\hline Echogenic endometrium with small cysts & Cystic hyperplasia \\
\hline In homogenous, irregular endometrial stripe & Atypical hyperplasia \\
\hline $\begin{array}{l}\text { Thick, solid, heterogeneous ill-defined } \\
\text { endometrial tissue }\end{array}$ & Endometrial carcinoma \\
\hline
\end{tabular}

\section{Procedure}

Informed and written consent was taken from all the patients.

1. Detailed clinical evaluation was done by noting the history of complaints followed by complete clinical examination. Routine investigations were done in all the cases.

2. On an empty bladder, a Trans-vaginal sonography with a $7.5 \mathrm{MHz}$ transducer was performed.

3. Endometrial thickness was noted as a two layer thickness in the antero-posterior dimension, that too only the maximally thick area was considered.

4. Dilatation and curettage procedure was carried out in the operation theater under short general anesthesia.

5. The endometrial sample was collected and sent to the histopathology section. There the tissue was processed by routine histopathology and the slides were examined by light microscopy.

6. The TVS findings and the histopathology findings were compared and correlated. 


\section{Results}

Table 1: Age distribution of patients

\begin{tabular}{|l|c|c|}
\hline Age in years & No. of cases & Percentage (\%) \\
\hline $40-45$ & 27 & $36 \%$ \\
\hline $46-50$ & 25 & $33.33 \%$ \\
\hline $51-55$ & 15 & $20 \%$ \\
\hline $56-60$ & 8 & $10.66 \%$ \\
\hline Total & 75 & $100 \%$ \\
\hline
\end{tabular}

Majority of the patients were between $40-45$ years (27\%) in the present study.

Table 2: Clinical Presentation

\begin{tabular}{|l|c|c|}
\hline $\begin{array}{c}\text { Various menstrual } \\
\text { patterns }\end{array}$ & No. of cases & Percentage (\%) \\
\hline Menorrhagia & 30 & $40 \%$ \\
\hline Polymenorrhagia & 22 & $29.33 \%$ \\
\hline Postmenopausal bleeding & 23 & $30.66 \%$ \\
\hline Total & 75 & $100 \%$ \\
\hline
\end{tabular}

Among 75 patients, menorrhagia was present in 30 cases (40\%).

Table 3: Endometrial Thickness

\begin{tabular}{|l|l|l|}
\hline $\begin{array}{c}\text { Endometrial Thickness } \\
(\mathbf{m m})\end{array}$ & No. of cases & Percentage (\%) \\
\hline$<5 \mathrm{~mm}$ & 3 & $4 \%$ \\
\hline $5-8 \mathrm{~mm}$ & 18 & $24 \%$ \\
\hline $8-10 \mathrm{~mm}$ & 35 & $46.66 \%$ \\
\hline $10-15 \mathrm{~mm}$ & 15 & $20 \%$ \\
\hline$\geq 15 \mathrm{~mm}$ & 4 & $5.33 \%$ \\
\hline Total & 75 & $100 \%$ \\
\hline
\end{tabular}

In our study, 35 patients (46.66\%) had an ET between 8-10 mm and 15 patients (20\%) had an ET between 10-15 $\mathrm{mm}$.

Table 4 Correlation between endometrial thickness on TVS and endometrial hyperplasia

\begin{tabular}{|l|c|c|c|}
\hline $\begin{array}{c}\text { Endometrial } \\
\text { Thickness (mm) }\end{array}$ & No. of cases & $\begin{array}{c}\text { Endometrial } \\
\text { Hyperplasia }\end{array}$ & $\begin{array}{c}\text { Percentage } \\
(\mathbf{\%})\end{array}$ \\
\hline$<5 \mathrm{~mm}$ & 3 & 0 & 0 \\
\hline $5-8 \mathrm{~mm}$ & 18 & 0 & 0 \\
\hline $8-10 \mathrm{~mm}$ & 35 & 0 & 0 \\
\hline $10-15 \mathrm{~mm}$ & 15 & 20 & $66.66 \%$ \\
\hline$\geq 15 \mathrm{~mm}$ & 4 & 10 & $33.33 \%$ \\
\hline Total & 75 & 30 & $100 \%$ \\
\hline
\end{tabular}

Table 5: Endometrial patterns on histopathology

\begin{tabular}{|l|c|c|}
\hline $\begin{array}{c}\text { Histopathology of } \\
\text { endometrium }\end{array}$ & No. of cases & $\begin{array}{c}\text { Percentage } \\
(\mathbf{\%})\end{array}$ \\
\hline Proliferative endometrium & 25 & $33.33 \%$ \\
\hline Secretory endometrium & 15 & $20 \%$ \\
\hline Endometrial hyperplasia & 30 & $40 \%$ \\
\hline Atrophic endometrium & 3 & $4 \%$ \\
\hline Endometrial cancer & 2 & $2.66 \%$ \\
\hline Total & 75 & $100 \%$ \\
\hline
\end{tabular}


In our study, 30 (40\%) patients showed endometrial hyperplasia and $25(33.33 \%)$ patients showed proliferative type of endometrium.

Table 6: Morphology of endometrial hyperplasia

\begin{tabular}{|l|c|c|}
\hline $\begin{array}{c}\text { Type of endometrial } \\
\text { hyperplasia }\end{array}$ & No. of cases & $\begin{array}{c}\text { Percentage } \\
(\boldsymbol{\%})\end{array}$ \\
\hline Simple hyperplasia & 20 & $66.66 \%$ \\
\hline Complex hyperplasia & 8 & $26.66 \%$ \\
\hline Atypical hyperplasia & 2 & $6.66 \%$ \\
\hline Total & 30 & $100 \%$ \\
\hline
\end{tabular}

Among 30 patients of endometrial hyperplasia, only 2 patients (6.66\%) had atypical hyperplasia. Majority $66.66 \%$ had simple hyperplasia.

\section{Discussion}

Abnormal uterine bleeding (AUB) is any deviation from normal menstrual pattern and includes variation in the frequency of cycles which can be short or long, the regularity, increased or decreased duration of flow and also the amount of blood loss. About 10-15\% of women experience episodes of AUB during reproductive years. $50 \%$ of peri-menopausal women are affected by AUB. Till the recent past, dilatation and curettage was the method of choice for studying endometrial tissue.

Endometrial thickness taken as cut off in postmenopausal age is $4-5 \mathrm{~mm} .^{6}$ Sonographic measurement of endometrial thickness has to be done first in postmenopausal bleeding to decide whether further investigations are needed to rule out malignancy. ${ }^{7}$ Early diagnosis and immediate treatment can be started if asymptomatic postmenopausal patients are screened. ${ }^{8}$

Studying the endometrium by dilatation and curettage procedure has some inherent defects as it can miss the sampling of lesional tissue. Only 10\% postmenopausal women show some significant endometrial pathology by this method due to the sampling errors. Also as it is an invasive procedure, repeat sampling is difficult and not feasible.

Trans-vaginalsonography to measure endometrial thickness is easier and better. Also TVS is accurate and the more invasive $\mathrm{D}$ and $\mathrm{C}$ procedure can be avoided unless it is absolutely essential.

In our study, 30 patients had endometrial hyperplasia when the endometrial thickness exceeded $10 \mathrm{~mm}$. There was no evidence of hyperplasia when the endometrial thickness was less than $10 \mathrm{~mm}$.

In $10-25 \%$ of patients, dilatation and curettage alone may miss an existing endometrial pathology. Dilatation and curettage is associated with complications like perforation of uterus and infection which has led to new methods of endometrial sampling. ${ }^{9}$

Age distribution of patients in present study was between 40-45 years (27\%). Among the clinical presentation $30 \%$ were menorrhagia, $23 \%$ postmenopausal bleeding and $22 \%$ were with polymenorrhagia. Out of 75 cases, $4 \%$ had endometrial thickness $<5 \mathrm{~mm}, 18 \%$ had $5-8 \mathrm{~mm}, 35 \%$ with $8-10 \mathrm{~mm}$ thickness, $15 \%$ with $10-15 \mathrm{~mm}$ thickness and $4 \%$ with endometrial thickness $\geq 15 \mathrm{~mm}$.

Out of 75 patients of AUB, proliferative endometrium was seen in $25 \%$, secretory endometrium in $15 \%$, endometrial hyperplasia in $30 \%$, atypical hyperplasia in $6.66 \%$. In our study, hyperplasia was noted only when the endometrial thickness was above $10 \mathrm{~mm}$ cut-off value.

Biopsy or curettage has to be at an appropriate time so as to get tissue for diagnosis. ${ }^{10}$ Interpretation of $\mathrm{D}$ and $\mathrm{C}$ result requires clinical information like age, parity and menstrual history. ${ }^{11}$ Endometrial assessment by endometrial biopsy or curettage is indicated in perimenopausal and postmenopausal women to rule out endometrial hyperplasia or carcinoma. $^{12}$ Histopathological evaluation is a must to rule out malignancy in postmenopausal bleeding. ${ }^{13}$

\section{Conclusion}

Based on the findings of the above study, we conclude that in abnormal uterine bleeding, the first investigation should be transvaginal ultrasound. In perimenopausal patients if the endometrial thickness exceeds $10 \mathrm{~mm}$, a dilatation and curettage procedure is to be done to rule out any endometrial hyperplasia. No complications were seen with the procedure in this study. In postmenopausal women dilatation and curettage is recommended if endometrial thickness exceeds $5 \mathrm{~mm}$. The method of measuring the endometrium, the experience and skill of the radiologist influence the TVS results. Histopathology plays a major role in the definitive diagnosis.

\section{Compliance with ethical requirements and Conflict}

of interest: The study was approved by the institutional Ethical and Research Review Board. There is no conflict of interest.

\section{References}

1. Mishra D,Sultan S. FIGO'S PALM - COEIN Classification of abnormal uterine bleeding: A ClinicoHistopathological correlation in Indian setting. The 
Journal of Obstetrics and Gynecology of India. 2017;67:119-25.

2. Kotdawala P, Kotdawala S,Nagar N. Evaluation of endometrium in perimenopausal abnormal uterine bleeding.J Midlife Health. 2013;4:16-21.

3. Kaur M, Singh R,Sharma M. Endovaginal sonographic evaluation of postmenopausal uterine bleeding.J ClinDiagn Res. 2010;4:2175-82.

4. Bhosle A, Fonscea M. Evaluation and histopathological correlation ofabnormal uterine bleeding inperimenopausalwomen. Bombay HospJ 2010;52:69-72.

5. Evaluation and management of Postmenopausal bleeding. Indian Menopause Society. Guideline Number 4:August 2010.

6. Hebbar S, Chaya V, Rai L, Ramachandran A. Factors influencing endometrial thickness in postmenopausal women. Annals of Medical and Health sciences Research 2014;4:608-14.

7. Breijer MC, Peters JAH, Opmeer BC, Clark TJ, Verheijen RMH, B.W.J. mol,A. Timmerrmans. Capacity of endometrial thickness measurement to diagnose endometrial carcinoma in asymptomatic postmenopausal women: a systematic review and meta-analysis. Ultrasound ObstetGynecol 2012;40:621-9.

8. Thickened endometrium in asymptomatic postmenopausal women: Is biopsy mandatory? Med J Cairo Univ2011;79:723-7.

9. Khan S, Hameed S,Umber A. Histopathological pattern of endometrium on diagnostic D\&C in patients with abnormal uterine bleeding .ANNALS.2011;17:166-70.

10. Prajapati R, Daveshwar M. Clinic- pathological correlation of endometrial pattern in patients with abnormal uterine bleeding.Int J Res Med. 2015;4:128-32.

11. SajithaK, Shetty K, Padma K, Jayaprakash Shetty H,Kishan Prasad L, Permi HS, Hegde P: Study of histopathological patterns of endometrium in AUB.Chrismed Journal of Health and Research 2014;1:76-81.

12. Shobha Rani MS, Mallika M. Histopathological study of perimenopausal Abnormal uterine bleeding.Scholars Academic Journal of Biosciences2016;4:33-7.

13. Singh P,Diwivedi P, Mendiratta S. Correlation of endometrial thickness with the histopathological pattern of endometrium in postmenopausal bleeding. The journal of Obstetrics and Gynecology of India 2016;66:42-6. 